\title{
A U tilização de Instrumentos Econômicos em Bacias Hidrográficas Sujeitas à Mineração: O Caso da Região Carbonífera de Santa Catarina
}

\author{
Adriano de Paula Fontainhas Bandeira, Carlos André B. Mendes \\ Institu to de Pesquisas H idráulicas - UFRGS \\ adrianopfb@gmail.com, mendes@iph.ufrgs.br
}

Recebido: 20/09/07 -revisado: 27/09/08 -aceito: 28/09/09

\begin{abstract}
RESUMO
Os impactos ambientais provocados por determinadas atividades econômicas podem cau sar prejuízos fin an ceiros em terceiros já que o custo de compen sar ou aquele de evitar a ação deletéria sobre o meio preju dica e, em alguns casos, inviabiliza a existência de outras atividades econômicas. Nesse contexto, enquadra-se a mineração de carvão. Em tal atividade, 0 contato da água -superficial, subterrânea ou pluvial -com elementos espećficicos resultantes das escavações, na presença de oxigênio e de microorganismos, forma a chamada drenagem ácida de mina, que, em grande parte dos casos, é despejada em cursos d'água adjacentes prejudicando ou tros usos da água. A ssim, o presente trabalho tem por objetivo elaborar uma metodologia de planejamento da explotação do carvão mineral em bacias hidrográficas que bu sque a produção ótima do minério com a internalização dos custos de tratamento do efluente gerado a fim de que os parâmetros de qualidade da água sejam respeitados e, desse modo, não exista a incidência de prejuízos em terceiros. Tal metodologia é pautada pela elaboração deum modelo de otimização que seja capaz de representar, a o longo do tempo de exploração das minas, a carga de poluentes lançada nos cursos d'água de uma bacia hidrográfica.
\end{abstract}

Palavraschave Drenagem ácida de mina, Bacia H idrográfica, Otimização.

\section{INTRODUÇÃO}

O aparecimento de novas atividades aliadas à expansão daquelas existentes em determinada região provoca acréscimos na demanda por seus recursos naturais, dentre os quais se destaca a água. Assim, a ação de um produtor ou consumidor pode influenciar outros produtores ou consumidores. Quando isto acontece, sem que haja consideração na fixação do preço de mercado, diz-se que ocorreu uma externalidade. Esta pode ser positiva, quando 0 efeito é benéfico, ou negativa, no caso contrário (Pindyck; Rubinfeld, 2002).

No que se refere à utilização dos recursos hídricos, a ocorrência de externalidades é agravada por ser a água considerada um bem público, ou seja, aquele cujos consumidores não sofrem restrições para consumir e cujo custo de ampliação de consumo é nulo.

Assim surgem conflitos, protagonizados por empreendedores interessados em diluir resíduos de suas atividades ou em usar a água em determinada fase de seu processo de produção e pela população interessada no seu abastecimento e no despejo dos resíduos domésticos. Nesse contexto, cita-se o e- xemplo da atividade de mineração, em particular daquela relacionada à explotação de carvão. Quando o carvão é retirado, ele é acompanhado por grande quantidade de resíduos, que, depois de separados, são depositados em locais próximos às minas. A chuva, ao percolar através dos resíduos, reage com eles produzindo elementos nocivos. Em paraleIo, a lavra subterrânea pode permitir o contato do minério com o lençol freático. 0 líquido resultante é o efluente conhecido como DAM (Drenagem Ácida de Mina). A DAM pode escoar na superfície do terreno até os cursos d'água, onde são adicionados aos poluentes já transportados, ou infiltrar no solo, contaminando águas subterrâneas. Após a explotação da mina, o lançamento da DAM no meio ambiente pode persistir, pois, em geral, as minas são abandonadas sem que haja uma preparação para evitar tal despejo.

Existem diversas formas de tratamento de DAM. Sua utilização, no entanto, é pouco realizada por apresentar al tos custos.

\section{H ipótese e Q uestão de Pesquisa}

0 presente estudo partiu da premissa de que o planejamento de uso dos recursos hídricos 
por parte da atividade de mineração traz benefícios à sociedade. Os empreendedores tornam-se menos suscetíveis a custos imprevistos, causados por terceiros, e, portanto, podem fazer um planejamento mais adequado de suas atividades. Supõe-se, também, que todas as empresas mineradoras instaladas na bacia estejam envolvidas no planejamento, embora exista alguma resistência ao processo devido ao receio de surgimento de despesas extras.

0 estudo tem como objetivo geral responder à seguinte questão: A internalização dos custos de recomposição da área degradada e dos custos de tratamento de efluentes a fim de atender aos limites de concentração de parâmetros de qualidade da água (estabelecidos pela Resolução 357 do CONAMA) pode inviabilizar a explotação mineral?

A Bacia Hidrográfica como unidade de planejamento de uso dos recursos naturais

O uso da bacia hidrográfica, como unidade de estudo, para o gerenciamento das diferentes formas de ocupação e uso das potencialidades ambientais tem como objetivo planejar, coordenar, executar e manejar as melhores formas de apropriação e explotação de seus recursos ambientais, proporcionando o desenvolvimento socioeconômico das suas respectivas populações e a sustentabilidade dos recursos ambientais, diminuindo ou evitando a degradação da qualidade de vida (Bordallo, 1995). Segundo Lanna (1995), o gerenciamento de bacia hidrográfica $(\mathrm{GBH})$ é o instrumento que orienta 0 poder público e a sociedade, no longo prazo, na utilização e monitoramento dos recursos ambientais, naturais e econômicos, de forma a promover o desenvolvimento sustentável.

As abordagens de planejamento e gerenciamento que utilizam a bacia hidrográfica como unidade de trabalho têm evoluído bastante, pois suas características biogeofísicas apresentam sistemas ecológicos e hidrológicos coesos (Pires; Santos, 1995).

Drenagem ácida de mina (DAM)

A DAM é resultado de um conhecido processo químico. Em contato com ar, água e microorganismos, minerais ricos em enxofre, como a pirita $\left(\mathrm{FeS}_{2}\right)$, se oxidam e produzem ácido sulfúrico. Concomitantemente, ferro e outros metais são descarregados na água. 0 problema pode ser associado com a extração de carvão ou com a escavação de rochas nas quais minerais sulfurosos, antes no subsolo, entram em contato com o oxigênio e com a água. Gu- sek (2005) apresenta as quatro reações do processo de formação de DAM :

$$
\begin{aligned}
& \mathrm{FeS}_{2}+\frac{7}{2} \mathrm{O}_{2}+\mathrm{H}_{2} \mathrm{O} \rightarrow \mathrm{Fe}^{2+}+2 \mathrm{SO}_{4}{ }^{2-}+2 \mathrm{H}^{+} \\
& \mathrm{Fe}^{2+}+\frac{1}{4} \mathrm{O}_{2}+\mathrm{H}^{+} \rightarrow \mathrm{Fe}^{3+}+\frac{1}{2} \mathrm{H}_{2} \mathrm{O} \\
& \mathrm{Fe}^{3+}+3 \mathrm{H}_{2} \mathrm{O} \rightarrow \mathrm{Fe}(\mathrm{OH})_{3}+3 \mathrm{H}^{+} \\
& \mathrm{FeS}_{2}+14 \mathrm{Fe}^{3+}+8 \mathrm{H}_{2} \mathrm{O} \rightarrow \\
& \mathrm{IFFe}^{2+}+2 \mathrm{SO}_{4}{ }^{2-}+16 \mathrm{H}^{+}
\end{aligned}
$$

Em solução com baixo pH, as reações (1), (2) e (4) são catalisadas por organismos unicelulares que aceleram a oxidação da pirita fazendo com que a acidez aumente. 0 aumento da acidez provoca a dissolução de outros metais pesados (Stumm et al. apud Seyler, 2003). Dessa forma, pode haver a contaminação da água também por cobre, zinco, chumbo e manganês, entre outros metais.

Assim, de forma análoga ao triângulo do fogo, o qual apresenta os elementos necessários para a combustão (oxigênio, combustível e calor), pode-se elaborar o tetraedro da DAM mostrando-se os elementos imprescindíveis à formação da substância.

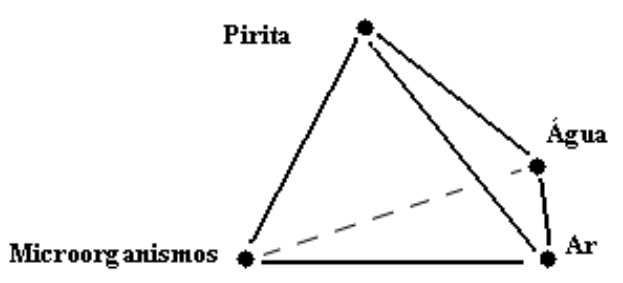

Figura 1 - T etraedro de DAM.

Tecnologias de extração de carvão mineral

A escolha do método de mineração é determinada pela geologia apresentada no local de extração. Assim, a combinação da profundidade da camada de carvão e do tipo de solo que a cobre estabelece se a forma de explotação será subterrânea ou de superfície.

A explotação subterrânea se dá, em geral, quando a camada de carvão mineral está localizada em grandes profundidades ou quando a camada de solo e rochas que a cobre (overburden) apresenta 
dificuldades de remoção. A explotação superficial apresenta viabilidade econômica quando a camada de carvão se localiza próxima ao nível do terreno. Ela consiste na escavação e remoção da camada de solo e rochas que cobre o carvão mineral. A partir daí, com o carvão exposto, a explotação, propriamente dita, se inicia ( WCI, 2005).

Em relação à contaminação dos corpos d'água, especial atenção deve ser dada à entrada de águas pluviais nas escavações. A retirada do overburden, o beneficiamento e a construção de vias de acesso, são responsáveis pela alteração da drenagem natural do terreno e do regime de infiltração e retenção de água no subsolo (Gibson, 1987).

Tecnologias de tratamento de resíduos

As formas de tratamento de resíduos de 0perações de minas são classificadas em ações para o tratamento de efluentes e ações para a desmobilização do empreendimento. As ações para o tratamento do efluente são, por sua vez, classificadas como tratamento passivo e tratamento ativo.

As principais estruturas para a realização do tratamento passivo são as lagoas anaeróbica e aeróbica, o canal calcário óxico, o dreno calcário anóxico, a bacia de fluxo vertical (BFV) e o leito de remoção de manganês (LRM). As lagoas, a BFV e o LRM são estruturas semelhantes que consistem em uma escavação trapezoidal para onde é conduzido o efluente (DAM). A lagoa aeróbica apresenta uma cobertura vegetal para redução do oxigênio dissolvido e a anaeróbica possui também uma camada de calcário. A bacia de fluxo vertical também apresenta uma camada de matéria orgânica e uma de calcário, mas seu efluente é drenado pelo fundo da escavação. 0 leito de remoção de manganês não possui camada de matéria orgânica, mas apresenta uma espessa camada de calcário. O canal óxico e o dreno anóxico destinam-se à condução do efluente para as unidades de tratamento e para o destino final (em geral, os cursos d'água). A diferença ente eles consiste no fato de o dreno ser revestido. A tabela 1 apresenta as principais substâncias removidas pelo tratamento.

O tratamento ativo de drenagem ácida de mina consiste na adição de um reagente químico que seja capaz de provocar a precipitação de substâncias contaminantes a fim de que estas sejam posteriormente removidas. É mais utilizado em águas com elevado grau de contaminação ou quando há pouca disponibilidade de espaço (Coulton et al, 2005).
Os principais reagentes utilizados no tratamento ativo são o hidróxido de sódio (soda cáustica, $\mathrm{Na}$ $\mathrm{OH})$, cal hidratada $\left(\mathrm{Ca}(\mathrm{OH})_{2}\right)$, cal virgem $(\mathrm{CaO})$ e amônia $\left(\mathrm{NH}_{3}\right)$. Também podem ser utilizados 0 óxido de magnésio $(\mathrm{MgO})$, o hidróxido de magnésio $\left(\mathrm{Mg}(\mathrm{OH})_{2}\right)$ e o carbonato de sódio $\left(\mathrm{Na}_{2} \mathrm{CO}_{3}\right)$.

Tabela 1 - Contaminante objeto do tratamento.

\begin{tabular}{|l|l|}
\hline $\begin{array}{l}\text { TECN O LO GIA DE } \\
\text { TRATAMENTO PASSIVO }\end{array}$ & $\begin{array}{l}\text { ELEMENTO-ALVO } \\
\text { DO TRAT AMENTO }\end{array}$ \\
\hline Lagoa Anaeróbica & $\mathrm{SO}_{4}$, acidez \\
\hline Lagoa Aeróbica & $\mathrm{Fe}, \mathrm{U}, \mathrm{Mg}, \mathrm{As}, \mathrm{CN}$ \\
\hline Canal calcário óxico & $\mathrm{Acidez}, \mathrm{Zn}, \mathrm{Cd}, \mathrm{As}, \mathrm{Mg}, \mathrm{Ca}$ \\
\hline Dreno calcário anóxico & Acidez, $\mathrm{Zn}, \mathrm{Cd}, \mathrm{As}, \mathrm{Mg}, \mathrm{Ca}$ \\
\hline Bacia de fluxo vertical & $\mathrm{Acidez}, \mathrm{SO} 4$ \\
\hline $\begin{array}{l}\text { Leito de remoção de man- } \\
\text { ganês }\end{array}$ & $\mathrm{Mn}$ \\
\hline
\end{tabular}

Adaptada de Rees, 2005.

Desmobilização do empreendimento mineiro

A desmobilização do empreendimento mineiro é determinada pelo parágrafo 20 do artigo 225 da Constituição Federal Brasileira, o qual estabelece que "aquele que explorar recursos minerais fica obrigado a recuperar o meio ambiente degradado, de acordo com solução técnica exigida pelo órgão público competente, na forma da lei" (BRASIL, 1988).

O tratamento de recomposição considerado no presente estudo é constituído por um trabalho de terraplenagem que consiste, apenas, no assentamento de uma camada de solo sobre a área impactada. Tal camada pode ser revestida com vegetação, impermeabilizada pela urbanização ou, ainda, não possuir revestimento algum.

\section{METODOLOGIA}

Conrad e Clarke (1987) estabelecem um modelo da dinâmica de exploração dos recursos não-renováveis. Sejam $X(t)$ e $w(t)$, respectivamente, as descobertas acumuladas e 0 esforço de exploração. Sejam, ainda, $R(t)$ e $q(t)$ a reserva disponível e a quantidade extraída no tempo t. Pode-se dizer que: 


$$
\begin{aligned}
& \frac{\partial R(t)}{\partial t}=\frac{\partial X(t)}{\partial t}-q(t) \\
& \frac{\partial X(t)}{\partial t}=f(w(t), X(t))
\end{aligned}
$$

Em outras palavras, a variação da reserva de recurso com o tempo depende da variação das novas descobertas com o tempo e da produção mineral. Assim, tem-se que: $\partial f / \partial w>0$, pois quanto maior 0 esforço de exploração, mais descobertas serão feitas; e $\partial f / \partial X<0$, pois à medida que novas descobertas são feitas, menores são as chances de que sejam realizadas outras descobertas.

Sejam $C_{i}\left(q_{i}(t)\right)$ o custo de extração da iésima mineradora, $R_{i}$ suas reservas iniciais e $p$ preço de venda do minério em um mercado competitivo. Cada firma tenta maximizar os lucros de acordo com a seguinte formulação matemática, na qual $\delta$ refere-se à taxa de juros:

Max

$$
\pi=\int_{0}^{T_{i}}[p(t) q(t)-C(q(t))-C(w(t))] e^{-\delta t} d t
$$

Sujeito a:

$$
\begin{aligned}
& R(t+1)-R(t)=f(w(t), X(t))-q(t) \\
& R_{i}(0)=R_{i} \\
& \frac{\partial X}{\partial t}=f(w(t), X(t)) \\
& X(0)=0
\end{aligned}
$$

As restrições significam, respectivamente, que a variação da reserva com o tempo é igual, em módulo, à diferença entre descobertas e produção da mina; a reserva inicial de cada mina é igual à reserva total estimada; as novas descobertas variam conforme o esforço para realizá-las e a quantidade de descobertas já realizadas; e no início da operação não se consideram novas descobertas.

\section{O btenção de dados}

Os dados necessários para o modelo podem ser divididos em dados da bacia, dados relacionados

\begin{tabular}{|c|c|}
\hline \multicolumn{2}{|c|}{ VARIÁVEIS DA BACIA } \\
\hline $\mathrm{Q}(\mathrm{i}, \mathrm{t})$ & Vazão mensal nos cursos d'água \\
\hline$P(t)$ & Precipitação mensal \\
\hline $\operatorname{Lim}(I)$ & Limite tolerável de cada contaminante \\
\hline Qsub (t) & Vazão oriunda do lençol freático \\
\hline \multicolumn{2}{|c|}{ VARIÁVEIS DE EXTRAÇÃO } \\
\hline & Índice das minas \\
\hline$T(i)$ & Tempo de explotação das minas \\
\hline$A(i)$ & $\begin{array}{l}\text { Área de superfície minerada de cada } \\
\text { mina }\end{array}$ \\
\hline $\mathrm{R}_{0}(\mathrm{i})$ & Reserva inicial da mina i \\
\hline$p$ & Preço da tonelada de carvão \\
\hline 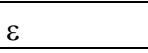 & Percentual de rejeit \\
\hline ex & Alternativas de explotação \\
\hline CExp (i) & Custo fixo de explotação de cada mina \\
\hline CBen (i) & Custo de beneficiamento do carvão \\
\hline$\delta$ & Taxa de juros \\
\hline \multicolumn{2}{|c|}{ VARIÁVEIS DE TRATAMENTO DE EFLUENTES } \\
\hline & Alternativas de tratamento de efluentes \\
\hline CTrat (i) & $\begin{array}{l}\text { Custo de tratamento de efluentes da } \\
\text { mina i }\end{array}$ \\
\hline & Contaminante considerado \\
\hline Conc $(\mathrm{l}, \mathrm{i})$ & Concentração de I na DAM da mina i \\
\hline$\eta(\mathrm{l}, \mathrm{i})$ & Percentual remanescente de I na mina i \\
\hline \multicolumn{2}{|c|}{ VARIAVEL DE FECH AMENTO DA MINA } \\
\hline CFec(i) & Custo para recompor a área da mina i \\
\hline
\end{tabular}

à extração do carvão mineral e ao tratamento do minério, dados relacionados ao tratamento de efluentes e dados relacionados ao fechamento do empreendimento. A tabela 2 exibe os dados necessários ao desenvolvimento do estudo.

T abela 2 - Variáveis de entrada.

Construção de funções econômicas e de equações de restrição

As funções econômicas necessárias para o desenvolvimento do modelo dizem respeito à receita da mineradora, aos seus custos de extração e de beneficiamento e aos seus custos de tratamento de efluentes e de fechamento de mina.

A receita da mineradora pode ser dada pelo produto entre a quantidade de minério por ela produzida (run of mine-ROM) e o preço unitário do carvão mineral, descontando-se a quantidade de resíduos presentes por tonelada de ROM:

$\operatorname{Receita}=p \bullet q(i, t) \bullet(1-\varepsilon)$ 
Os custos de extração do carvão mineral dependem da tecnologia de extração adotada pela empresa ou analisada no cenário proposto. Assim, com base nos dados apresentados formula-se a equação 13.

$$
\text { Extração }=\operatorname{CExp}_{e x}(i) \bullet q(i, t)
$$

Os custos de tratamento de efluentes serão divididos em parcelas mensais ao longo do tempo de explotação da mina. Assim, as parcelas do custo de tratamento $\mathrm{j}$ ( $C$ trat $_{\mathrm{j}}$ ) terão seu valor dado pela equação 14, onde M corresponde ao valor total do tratamento.

$\operatorname{CTrat}_{j}(i)=\frac{M_{0_{i j}}(1+\delta)^{t} \delta}{(1+\delta)^{t}-1}$

Por fim os custos de fechamento são dados pelas ações de terraplenagem necessárias à execução de uma cobertura na área da mina e são representados pela equação 15 , onde $\mathrm{M}_{\mathrm{id}}$ corresponde ao custo total de fechamento.

$\operatorname{CFec}_{d}(i)=\frac{M_{i d} \delta}{(1+\delta)^{t}-1}$

As restrições consideradas no modelo são referentes ao balanço de massa e à concentração de poluentes nos cursos d'água. 0 balanço de massa é dado pela equação 16 .

$R(i, t)=R(i, t-1)-q(i, t)$

No entanto, deve ser considerada a reserva inicial de cada jazida, bem como o seu esgotamento ao final do tempo de explotação. Tais restrições são dadas, respectivamente, pelas equações 17 e 18.

$R(i, t=0)=R_{i}$

$R(i, t=T)=0$

Para a concentração de poluentes nos cursos d'água são necessárias as seções dos rios onde são analisados os limites de concentração de contaminantes (aquelas nas quais as minas despejam seus efluentes), os limites de concentração toleráveis do poluente I ( $\operatorname{Lim}(I))$ e as vazões mensais do rio no trecho considerado e no tempo $t(\mathrm{Q}(\mathrm{i}, \mathrm{t}))$.
Seja, ainda, a carga de poluentes despejada nos rios da bacia hidrográfica em estudo dada pelo produto entre a vazão do efluente do tratamento e a concentração de cada contaminante após o devido tratamento. Assim, formula-se a equação 19.

$C \arg a(l, i, t)=Q_{\text {effuente }}(i, t) \bullet \eta(i, t) \bullet \operatorname{Conc}(l, i)$

Para que seja possível a comparação da descarga de contaminantes com os valores de concentração previstos em lei, deve-se dividir o valor encontrado acima pela vazão no trecho de rio receptor dos efluentes da mina considerada. Então, a contaminação causada por uma mina pode ser escrita conforme a equação 20.

$\operatorname{Cont}(l, i, t)=\frac{Q_{\text {efluente }}(i, t) \bullet \eta(i, t) \bullet \operatorname{Conc}(l, i)}{Q(i, t)}$

Sabe-se que a vazão efluente de cada mina varia com o tempo, pois é fruto de características hidrológicas locais, tais como precipitação e vazão oriunda de aqüíferos subterrâneos. A esse respeito, ressalta-se que a água precipitada diretamente nas minas, ou aquela que para ela flui devido às alterações da drenagem na área minerada, é esgotada em sua totalidade e descarregada para tratamento.

Além disso, contribui o processo de beneficiamento do carvão mineral para um maior volume de despejos, já que para cada tonelada de minério extraída é necessária uma quantidade de água (K) para que se consiga separar os resíduos. Dessa forma a vazão efluente mensal ( $Q$ efluente) originada por cada mina pode ser dada pela equação 21 .

$Q_{\text {effuente }}(i, t)=\operatorname{Prec}(i, t) \bullet A(i)+Q s u b t(i, t)+K \bullet q(i, t)(21)$

De posse de tais parâmetros, pode-se construir o conjunto de restrições dado pela equação 22 .

$$
\frac{\sum_{i=1}^{m} Q_{\text {efluente }}(i, t) \bullet \eta(i, t) \bullet \operatorname{Conc}(l, i)}{Q(i, t)} \leq \operatorname{Lim}(l)
$$

A variação do somatório de 1 a $m$ refere-se às minas que contribuem para o acúmulo de contaminantes em determinada seção de rio e o parâmetro Lim (I) diz respeito à concentração de determinado contaminante permitida. Cabe salientar que 
não está sendo considerado o fenômeno de autodepuração dos cursos d'águas.

\section{Aplicação do modelo de otimização}

Para a aplicação do modelo adota-se a discretização mensal do tempo. 0 objetivo do modelo é a maximização do valor presente líquido (VPL) sob a consideração do despejo de efluentes em uma bacia hidrográfica. As restrições são o balanço de massa e o limite de concentração de contaminantes.

Matematicamente:

$\operatorname{Max} \sum_{i=1}^{I} \sum_{t=1}^{T} \rho^{t}\left[p \bullet q(i, t) \bullet(1-\varepsilon)-C \operatorname{Exp}_{p_{x}}(i) \bullet q(i, t)-\right]$

Sujeito a:

$R(i, t=0)=R(i)$

$R(i, t)=R(i, t-1)-q(i, t)$

$R(i, t=T)=0$

$\frac{\sum_{i=1}^{m} Q_{\text {efluente }}(i, t) \bullet \eta(i, t) \bullet \operatorname{Conc}(l, i)}{Q(i, t)} \leq \operatorname{Lim}(l)$

\section{RESULTADOS}

0 presente modelo foi aplicado com quatro cenários distintos, utilizando como área de estudo a sub-bacia do Rio Sangão.

\section{A sub-bacia do Rio Sangão}

O presente trabalho será focado na área drenada pelo Rio Sangão, a qual representa uma sub-bacia do Rio Araranguá. A figura 2 exibe a localização da área.

Em sua nascente, o Rio Sangão já apresenta pH próximo de 3,0, altas concentrações de sulfatose de metais pesados. 0 rio recebe contribuições de efluentes industriais (cerâmica, metal-mecânica, vestuários, curtumes etc.), hospitalares, urbanos, além de atividades ligadas à exploração e beneficiamento de carvão mineral. No presente trabalho, considera-se apenas a existências de atividade de mineração. De forma esquemática, pode-se repre- sentar a sub-bacia do Rio Sangão conforme a figura 3.

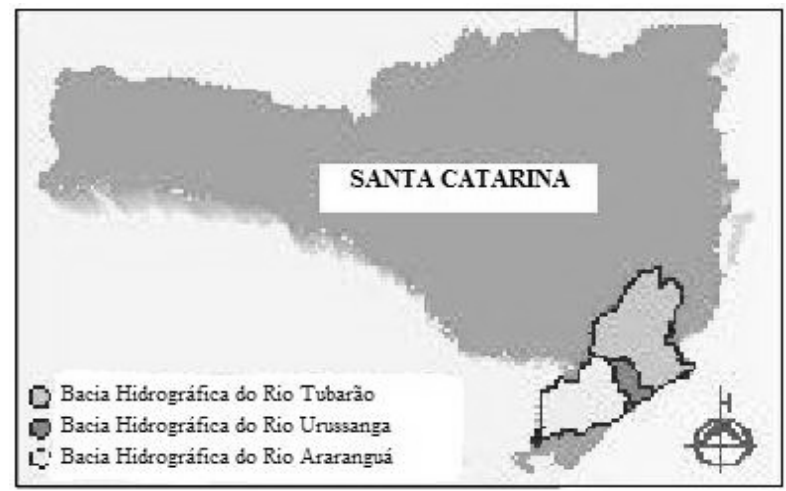

Figura 2 - Localização das Bacias dos Rios Tubarão, U russanga e Araranguá. Adaptada de Gomes, 2005.

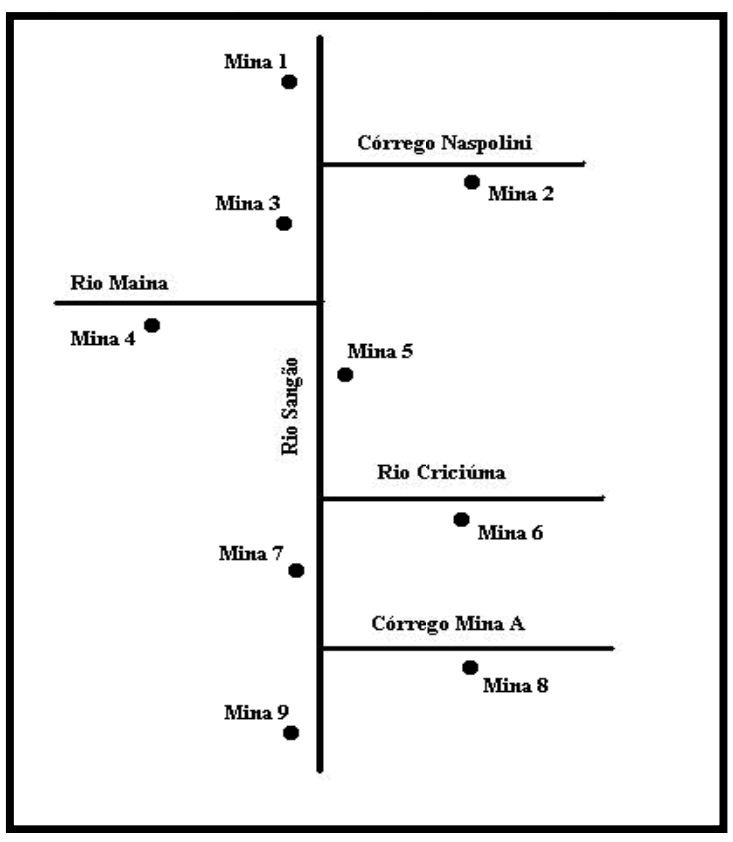

Figura 3 - Desenho Esquemático da sub-bacia do Rio Sangão.

Dados hidrometeorológicos da sub-bacia do Rio Sangão

Os rios formadores da sub-bacia do Rio Sangão não possuem postos de medição sendo, portanto, necessária uma abordagem de regionalização para a caracterização hidrológica da Bacia do Rio Araranguá em qualquer seção fluvial (SANTA CATARINA, 1997a). As tabelas 3 e 4 apresentam as vazões mensais dos rios da sub-bacia do Rio Sangão. 
Tabela 3 - Vazões mínimas em $\mathrm{m}^{3}$ / s no trecho norte da bacia do Rio Sangão.

\begin{tabular}{llll}
\hline Mês & $\begin{array}{l}\text { Rio Sangão } \\
\text { (trecho } \\
\text { te) }\end{array}$ & $\begin{array}{l}\text { Córrego } \\
\text { Naspolini }\end{array}$ & Rio Maina \\
\hline Jan & 0,374 & 0,014 & 0,048 \\
Fev & 0,675 & 0,026 & 0,086 \\
Mar & 0,531 & 0,020 & 0,068 \\
Abr & 0,470 & 0,018 & 0,060 \\
Mai & 0,320 & 0,012 & 0,041 \\
Jun & 0,278 & 0,011 & 0,035 \\
Jul & 0,349 & 0,013 & 0,044 \\
Ago & 0,308 & 0,012 & 0,039 \\
Set & 0,393 & 0,015 & 0,050 \\
Out & 0,405 & 0,015 & 0,052 \\
Nov & 0,335 & 0,013 & 0,043 \\
Dez & 0,369 & 0,014 & 0,047 \\
\hline & Adaptada de Santa Catarina, $1997 a$
\end{tabular}

Tabela 4 - Vazões mínimas em $\mathrm{m}^{3}$ / s no trecho sul da bacia do Rio Sangão.

\begin{tabular}{llll}
\hline Mês & $\begin{array}{l}\text { Rio } \\
\text { (trecho sul) }\end{array}$ & $\begin{array}{l}\text { Sangão } \\
\text { úma }\end{array}$ & $\begin{array}{l}\text { Crici- } \\
\text { Mina A } A\end{array}$ \\
\hline Jan & 0,321 & 0,027 & 0,007 \\
Fev & 0,580 & 0,048 & 0,012 \\
Mar & 0,456 & 0,038 & 0,010 \\
Abr & 0,404 & 0,034 & 0,008 \\
Mai & 0,275 & 0,023 & 0,006 \\
Jun & 0,239 & 0,020 & 0,005 \\
Jul & 0,299 & 0,025 & 0,006 \\
Ago & 0,264 & 0,022 & 0,006 \\
Set & 0,337 & 0,028 & 0,007 \\
Out & 0,348 & 0,029 & 0,007 \\
Nov & 0,287 & 0,024 & 0,006 \\
Dez & 0,317 & 0,026 & 0,007 \\
\hline \multicolumn{4}{l}{ Adaptada de Santa Catarina, $1997 a}$.
\end{tabular}

Como não há estações pluviométricas localizadas na sub-bacia do Rio Sangão, a precipitação é considerada constante em todos os pontos onde há minas na área de estudo. No presente trabalho, considera-se que a vazão mensal bombeada para fora das minas corresponde ao volume de água precipitado sobre a área de superfície minerada. Os valores de precipitação adotados referem-se à medição realizada no município de Forquilhinha, vizinho ao município de Criciúma, onde se localiza parte da sub-bacia do rio Sangão. A tabela 5 exibe os valores adotados.

Tabela 5 - Valores de precipitação adotados no modelo.

\begin{tabular}{ll}
\hline Mês & $\begin{array}{l}\text { Precipitação } \\
(\mathrm{mm})\end{array}$ \\
\hline Jan & 170,28 \\
Fev & 188,35 \\
Mar & 129,09 \\
Abr & 99,87 \\
Mai & 98,84 \\
Jun & 96,05 \\
Jul & 123,71 \\
Ago & 104,22 \\
Set & 124,63 \\
O ut & 135,62 \\
Nov & 132,73 \\
Dez & 162,82 \\
\hline Adaptada de Gomes, 2005.
\end{tabular}

\section{Condições de qualidade da água}

Gomes (2005) relata a concentração média dos principais componentes da drenagem ácida de treze bocas de minas abandonadas nas bacias hidrográficas dos Rios Araranguá e U russanga. A tabela 5 exibe tais concentrações, além do valor de $\mathrm{pH}$, e compara com os valores da Resolução Conama 257.

Tabela 6 - Padrões estabelecidos pelo Conama e composição da DAM nas minas da bacia do Rio Araranguá.

\begin{tabular}{|c|c|c|c|}
\hline Parâmetro & $\begin{array}{l}\text { Padrão } \\
\text { Classe } 1\end{array}$ & $\begin{array}{l}\text { Padrão } \\
\text { Classe } 3\end{array}$ & $\begin{array}{l}\text { Padrão } \\
\text { apresentado } \\
\text { na bacia }\end{array}$ \\
\hline & Entre 6,0 & & \\
\hline $\mathrm{pH}$ & 9,0 & Entre 6,0 e 9,0 & 3,17 \\
\hline $\mathrm{Fe}$ & $0,3 \mathrm{mg} / \mathrm{L}$ & $5,0 \mathrm{mg} / \mathrm{L}$ & $29,48 \mathrm{mg} / \mathrm{L}$ \\
\hline $\mathrm{Al}$ & $0,1 \mathrm{mg} / \mathrm{L}$ & $0,2 \mathrm{mg} / \mathrm{L}$ & $18,63 \mathrm{mg} / \mathrm{L}$ \\
\hline $\mathrm{Mn}$ & $0,1 \mathrm{mg} / \mathrm{L}$ & $0,5 \mathrm{mg} / \mathrm{L}$ & $2,63 \mathrm{mg} / \mathrm{L}$ \\
\hline $\mathrm{Zn}$ & $0,18 \mathrm{mg} / \mathrm{L}$ & $5,0 \mathrm{mg} / \mathrm{L}$ & $2,15 \mathrm{mg} / \mathrm{L}$ \\
\hline $\mathrm{Cu}$ & $0,009 \mathrm{mg} / \mathrm{L}$ & $0,013 \mathrm{mg} / \mathrm{L}$ & $0,001 \mathrm{mg} / \mathrm{L}$ \\
\hline Sulfatos & $250 \mathrm{mg} / \mathrm{L}$ & $250 \mathrm{mg} / \mathrm{L}$ & 1460 mg/ L \\
\hline
\end{tabular}

Adaptada de Gomes, 2005.

Dados relacionados à extração.

Os resíduos gerados no beneficiamento serão despejados no trecho de rio em cuja área de 
drenagem a mina se encontra. A verificação do atendimento aos parâmetros de qualidade da água será realizada no mesmo ponto. A tabela 6 apresenta a localização das minas, sua área aproximada, a reserva de minério e o tempo de explotação do carvão mineral.

Tabela 7 - Dados relacionados às minas.

\begin{tabular}{lllll}
\hline Mina & $\begin{array}{l}\text { Área } \\
\text { Minerada } \\
(\mathrm{m} 2)\end{array}$ & Receptor & $\begin{array}{l}\text { Reserva } \\
\left(\times 10^{6} \text { ton }\right)\end{array}$ & $\begin{array}{l}\text { Tempo de } \\
\text { explotação } \\
\text { (anos) }\end{array}$ \\
\hline Mina 1 & 17.500 & Sangão & 9,00 & 15 anos \\
Mina 2 & 10.000 & Naspolini & 6,00 & 15 anos \\
Mina 3 & 17.500 & Sangão & 9,00 & 15 anos \\
Mina 4 & 10.000 & Maina & 3,75 & 15 anos \\
Mina 5 & 17.500 & Sangão & 9,00 & 15 anos \\
Mina 6 & 4.000 & Criciúma & 4,50 & 15 anos \\
Mina 7 & 17.500 & Sangão & 9,00 & 15 anos \\
Mina 8 & 850 & Mina A & 3,00 & 15 anos \\
Mina 9 & 17.500 & Sangão & 9,00 & 15 anos \\
\hline
\end{tabular}

Segundo o SIECESC, o preço da tonelada de carvão beneficiado é de $R \$ 110,00$, considerandose a produção de CE $4.500 \mathrm{kcal} / \mathrm{kg}$ cujo índice de rejeitos é de, aproximadamente, $65 \%$. A taxa de juros considerada será de $0,8 \%$ ao mês. As minas da área de estudo são subterrâneas com utilização exclusiva da técnica de câmaras-e-pilares. 0 custo da lavra subterrânea, nesse caso, é de aproximadamente $\mathrm{R} \$ 30,00$ por tonelada ROM. 0 beneficiamento do carvão mineral tem um custo aproximado de $R \$ 3,00$ por tonelada, conforme informações cedidas pelo SIECESC.

Cumpre ressaltar que os dados apresentados variam de acordo com a empresa mineradora. No entanto, podem ser vistos como uma média apresentada pelas empresas estabelecidas na área de estudo.

Dados relacionados ao tratamento de efluentes

0 custo de tratamento de efluentes varia de acordo com a concentração de metais presentes na drenagem ácida. Segundo Gusek (2005), o custo de tratamento por quilograma de metal retirado do efluente, em preços de 1995, pode variar de US $\$ 0,33$ a US $\$ 0,38$ no caso de tratamento passivo. Para o tratamento ativo, o mesmo autor estima seu custo em US\$ 0,77. A tabela 8 relaciona tratamentos, custos e a remanescência de metais.
Tabela 8 - Tratamentos, custos e remanescências adotados.

\begin{tabular}{ccc}
\hline Tratamento & $\begin{array}{c}\text { Custo } \\
(\mathrm{R} \$ / \mathrm{Kg})\end{array}$ & $\begin{array}{c}\text { Percentual } \\
\text { Remanescente } \\
(\eta)\end{array}$ \\
\hline $\begin{array}{c}\text { Passivo simples } \\
\text { Passivo com }\end{array}$ & 1,12 & $2 \%$ \\
$\quad$ lagoa & & \\
anaeróbica & 1,29 & $1 \%$ \\
Ativo & 2,61 & 0 \\
\hline
\end{tabular}

Pode-se prever o volume de efluentes a tratar a partir da consideração de que são necessários 2 $\mathrm{m}^{3}$ de água para beneficiar uma tonelada de carvão mineral (SANTA CATARINA, 1997b). Soma-se ao volume de efluentes o produto da precipitação total ao longo do tempo da atividade pela área minerada para a determinação do volume de águas pluviais destinadas ao tratamento. A massa total de metais a tratar será o produto da concentração total de metais pelo volume de efluentes gerado.

Aplicando-se a Eq. (14), com a taxa de juros mensal de $0,8 \%$, nos valores totais, obtêm-se os custos de tratamento mensais. A tabela 9 apresenta tais custos arredondados para a centena superior mais próxima.

Tabela 9 - Parcelas mensais dos custos de tratamento

\begin{tabular}{llll}
\hline Minas & $\begin{array}{l}\text { Tratamento } \\
\text { passivo simples } \\
(\text { CT rat }\end{array}$ (i)) & $\begin{array}{l}\text { Tratamento } \\
\text { passivo } \\
\text { com lagoa } \\
\left.\text { anaeróbica } \text { (CTrat }_{2}(\mathrm{i})\right)\end{array}$ & $\begin{array}{l}\text { Tratamento } \\
\text { ativo } \\
(\mathrm{CT} \mathrm{rat}\end{array}$ (i)) \\
\hline Mina 1 & $\mathrm{R} \$ 11.500,00$ & $\mathrm{R} \$ 13.200,00$ & $\mathrm{R} \$ 26.700,00$ \\
Mina 2 & $\mathrm{R} \$ 7.700,00$ & $\mathrm{R} \$ 8.800,00$ & $\mathrm{R} \$ 17.800,00$ \\
Mina 3 & $\mathrm{R} \$ 11.500,00$ & $\mathrm{R} \$ 13.200,00$ & $\mathrm{R} \$ 26.700,00$ \\
Mina 4 & $\mathrm{R} \$ 4.700,00$ & $\mathrm{R} \$ 5.400,00$ & $\mathrm{R} \$ 11.000,00$ \\
Mina 5 & $\mathrm{R} \$ 11.500,00$ & $\mathrm{R} \$ 13.200,00$ & $\mathrm{R} \$ 26.700,00$ \\
Mina 6 & $\mathrm{R} \$ 5.700,00$ & $\mathrm{R} \$ 6.600,00$ & $\mathrm{R} \$ 13.200,00$ \\
Mina 7 & $\mathrm{R} \$ 11.500,00$ & $\mathrm{R} \$ 13.200,00$ & $\mathrm{R} \$ 26.700,00$ \\
Mina 8 & $\mathrm{R} \$ 3.800,00$ & $\mathrm{R} \$ 4.400,00$ & $\mathrm{R} \$ 8.800,00$ \\
Mina 9 & $\mathrm{R} \$ 11.500,00$ & $\mathrm{R} \$ 13.200,00$ & $\mathrm{R} \$ 26.700,00$ \\
\hline
\end{tabular}

Dados relacionados ao fechamento de mina

A previsão dos custos com o fechamento de mina é feita estimando-se quantidade de rejeitos produzidos pela explotação do carvão. Desse modo, a partir da reserva inicial estabelecida para cada 
mina e do percentual de rejeitos contidos no minério e, ainda, tendo em vista o fato de que as minas esgotam-se dentro de um tempo estabelecido, podese definir a quantidade de rejeito gerado. De posse da quantidade de rejeito a ser gerada durante a operação da mina, pode-se estimar o custo total de fechamento, tendo como base o valor de US\$ 0,80 por tonelada de rejeito, com taxa de juros de $0,8 \%$ ao mês. A tabela 10 apresenta os resultados obtidos com arredondamento para a centena superior mais próxima.

Tabela 10 - Custos mensais para o fechamento de mina.

\begin{tabular}{llrlr}
\hline Minas & \multicolumn{2}{l}{$\begin{array}{l}\text { Custo total } \\
\text { de fechamento }\end{array}$} & \multicolumn{2}{l}{$\begin{array}{l}\text { Custos mensais } \\
\text { de fechamento } \\
\text { (CFec(i)) }\end{array}$} \\
\hline Mina 1 & $\mathrm{R} \$$ & $10.530 .000,00$ & $\mathrm{R} \$$ & $20.100,00$ \\
Mina 2 & $\mathrm{R} \$$ & $7.020 .000,00$ & $\mathrm{R} \$$ & $13.400,00$ \\
Mina 3 & $\mathrm{R} \$$ & $10.530 .000,00$ & $\mathrm{R} \$$ & $20.100,00$ \\
Mina 4 & $\mathrm{R} \$$ & $4.287 .500,00$ & $\mathrm{R} \$$ & $8.400,00$ \\
Mina 5 & $\mathrm{R} \$$ & $10.530 .000,00$ & $\mathrm{R} \$$ & $20.100,00$ \\
Mina 6 & $\mathrm{R} \$$ & $5.265 .000,00$ & $\mathrm{R} \$$ & $10.100,00$ \\
Mina 7 & $\mathrm{R} \$$ & $10.530 .000,00$ & $\mathrm{R} \$$ & $20.100,00$ \\
Mina 8 & $\mathrm{R} \$$ & $3.510 .000,00$ & $\mathrm{R} \$$ & $6.700,00$ \\
Mina 9 & $\mathrm{R} \$$ & $10.530 .000,00$ & $\mathrm{R} \$$ & $20.100,00$ \\
\hline
\end{tabular}

Cenário 1 - 0 caso-base: sem tratamento de efluentes e sem plano de fechamento

O caso-base consiste na situação em que não há qualquer tipo de tratamento para o efluente gerado e não é considerada a responsabilidade de recomposição da área degradada. Assim sendo, verificou-se, aplicando a formulação matemática representada pelo conjunto de equações (23) a (26), o valor de $\mathrm{R} \$ 246.360 .674,38$ para a função-objetivo. Devido à ausência de tratamento, o valor encontrado é o maior entre os cenários analisados em detrimento da qualidade das águas da bacia. Conforme Wildemann (2005), um projeto que não integra 0 tratamento de efluentes e o fechamento do empreendimento é considerado um projeto fraco, pois provoca prejuízos futuros. O bservou-se que as minas de número ímpar, as situadas às margens do rio Sangão, apresentaram a mesma produção. Tal se deve ao fato de que, para essas minas, são idênticas as reservas iniciais. Verificou-se também que a maximização da produção impõe que as minas operem com sua máxima capacidade de produção no início do período analisado a fim de que se possa obter maior retorno financeiro, evidenciado pelo Valor Presente Líquido.

A falta de tratamento de efluentes fez com que fossem atingidas altas concentrações dos parâmetros analisados. No caso de ferro, verificaram-se valores quase mil vezes maiores que aqueles permitidos para enquadramento na classe $1(0,3 \mathrm{mg} / \mathrm{L}) \mathrm{e}$ cerca de 60 vezes maiores que o tolerável em enquadramento classe 3 (5,0 mg/ L). No caso de concentração de sulfatos foram atingidos valores 50 vezes maiores que o permitido para ambas as classes $(250 \mathrm{mg} / \mathrm{L})$. No caso do manganês o limite para classe $1(0,1 \mathrm{mg} / \mathrm{L})$ foi violado por valores cerca de 250 vezes maiores e para classe $3(0,5 \mathrm{mg} / \mathrm{L})$ por valores 50 vezes maiores.

Realiza-se, ainda, a tentativa de enquadramento das águas da bacia nas classes 1 e 3, respectivamente.

Cenário 2: enquadramento das águas da bacia na classe 1

Conforme apresentado no item anterior, a falta de tratamento de efluentes fez com que os parâmetros de qualidade da água analisados tivessem concentrações excedentes aos limites impostos pela lei. Portanto, para que tais limites sejam respeitados, é mister o emprego de técnicas de tratamento em todas as minas da bacia. No caso 1 , é realizada a tentativa de enquadramento das águas da bacia na classe 1.

Considera-se a forma intermediária de tratamento (passivo com lagoa anaeróbica) para as minas localizadas às margens do Rio Sangão, enquanto para as demais foi considerado o tratamento passivo simples. Verifica-se que dessa maneira não é possível o atendimento dos limites estabelecidos pela Resolução CONAMA para enquadramento das águas da bacia na classe 1 . Verificou-se que apenas as minas situadas no trecho norte do Rio Sangão ( $\operatorname{minas} 1,3$ e 5 ) conseguiram respeitar o limite de $0,3 \mathrm{mg} / \mathrm{L}$ imposto pela legislação. Este resultado pode ser justificado pela localização dessas minas a montante da bacia, onde o somatório das cargas poluentes ainda é pequeno.

A violação das restrições é mais acentuada nos casos das minas situadas nos afluentes do rio Sangão. Isto se deve à menor vazão desses rios o que eleva a concentração de qualquer contaminante descarregado em suas águas.

Assim sendo, realizam-se no presente estudo mais duas simulações. A primeira delas diz respeito ao enquadramento das águas na classe 3 e é denominada de caso 3. 0 caso 4 consiste da elevação dos 
gastos com tratamento de efluentes na tentativa de enquadrar as águas da bacia na classe 1 .

Cenário 3: enquadramento das águas da bacia na classe 3

Nesse caso, o valor final da função objetivo reduz-se, como era de se esperar, em relação ao caso base, e toma o valor de $R \$ 224.743 .760,66$. A diferença de rendimentos representa, aproximadamente, $8,77 \%$ do VPL obtido no caso base. Ressalta-se, no entanto, que se incluem na redução do VPL os gastos com o fechamento das minas, os quais no caso base não deixariam de existir. Ademais, o respeito aos parâmetros de qualidade da água possibilita a existência de outras atividades econômicas que dela dependam, fazendo com que toda a sociedade tenha benefício.

Cenário 4: elevação dos gastos com tratamento de efluentes para enquadramento na classe 1 .

Para que os limites sejam respeitados, é necessário o emprego de técnicas de tratamento que sejam capazes de garantir uma maior redução das cargas, ainda que para isso se devam elevar os gastos com tratamento. Assim, no caso 2, não se adota o tratamento passivo simples. Seis minas terão 0 tratamento ativo de seus efluentes $(1,2,3,5,6$ e 8$)$ e três delas ( 4,7 e 9$)$ terão o tratamento passivo com lagoa anaeróbica. Dessa forma, obtém-se o valor de $\mathrm{R} \$$ 218.585.329,07 para a função objetivo, o que implica uma redução de $11,27 \%$ em relação ao caso base.

Verificou-se que a mina 4, a qual recebeu a forma intermediária de tratamento, teve de diminuir sua produção nos primeiros meses de operação a fim de atender os limites para enquadramento na classe 1. Observou-se, ainda, que nos meses em que a concentração de ferro atinge o limite máximo previsto na lei, a produção de minério da mina 4 é diminuída, fazendo com que seja gerada uma menor vazão efluente e, em conseqüência, se reduzam as emissões de cargas poluentes.

U ma alternativa para o respeito à classificação das águas da bacia como Classe 1 seria a operação das minas em momentos diferentes. Em outras palavras, o órgão responsável pela emissão de licenças poderia permitir a exploração de minas situadas em uma área da bacia, liberando novos empreendimentos apenas quando tais minas fossem desmobilizadas. Tal alternativa não foi avaliada no presente trabalho.

\section{CONCLUSÃO}

Pode-se concluir que, com o uso do modelo elaborado, é possível realizar a internalização dos custos ambientais na atividade de mineração de carvão e, assim, reduzir a incidência de prejuízos em outros agentes decorrentes da poluição dos cursos d'água. Ademais, percebe-se que tal internalização pode, ainda, caracterizar corte de despesas tendo em vista que reduz gastos imprevistos, impedindo que o empreendedor seja surpreendido com despesas extras. A esse respeito, cumpre salientar o efeito positivo da distribuição, ao longo do período de explotação, de parte dos custos de fechamento, 0 que reduz sua concentração nos períodos finais mais críticos pela diminuição de rendimentos. Ainda quanto à internalização dos custos ambientais, destaca-se que ações tardias podem consumir os ganhos realizados pelos custos acumulados, causados, inclusive, por ações legais.

A utilização da bacia hidrográfica como unidade de estudo mostra-se uma metodologia eficaz de controle da poluição das águas superficiais, pois a propagação e o transporte dos sedimentos se dão por elas. Cabe, ainda, ressaltar que foram utilizados os valores de vazões mínimas mensais, o que, tornou a situação bastante restritiva, porém coerente quanto aos aspectos preventivos.

Por fim, cabe destacar mais uma vez, que é possível internalizar os custos ambientais e, assim, respeitar a classificação de uso das águas sem que isso inviabilize a mineração de carvão.

Limitações e Proposta de novos trabal hos

Ressalta-se a utilidade do modelo apresentado para os órgãos de controle e fiscalização de bacias hidrográficas. U m novo tema seria a aplicação de modelo semelhante para diversas atividades econômicas instaladas na bacia.

Com uma dinâmica hidrológica distinta daquela verificada no escoamento das águas superficiais, as águas subterrâneas não foram consideradas no modelo. Assim, deixou-se de analisar a questão da contaminação dos aqüíferos subterrâneos, tema de relevada importância à sociedade.

\section{REFERÊNCIAS}

BORDALLO, C. L. A (1995). A Bacia Hidrográfica como unidade de planejamento dos recursos hídricos. NUMA/UFPA. Belém. 
BRASIL, 1988. Constituição (1988). Constituição da República Federativa do Brasil. Brasília, DF: Senado.

CONAMA. Resolução n. 357 de 18 de mar. de 2005. Dispõe sobre a classificação dos corpos de água e diretrizes ambientais para o seu enquadramento, bem como estabelece as condições e padrões de lançamento de efluentes, e dá outras providências. Disponivel em www.mma.gov.br, acesso em 12 de mar. de 2006.

CONRAD, J.M., CLARKE, C.W (1987). Natural Resource Economics: Notes and Problems. Cambridge: Cambridge University Press, 231p.

COULTON, R., WILLIAMS, K (2005). Active Treatment of Mine Water: A European Perspective. In: Contemporary Reviews of Mine Water Studies in Europe, Part 2. Mine Water and the Environment, vol. 24 (4), p. 2326.

GIBSON, J. (1987). Coal and the Environment. Rio de Janeiro: Science Reviews, 59p.

GOMES, C. Projeto de Recuperação Ambiental: Áreas Impactadas Pela Mineração de Carvão. Apresentado no ! Workshop da Companhia Vale do Rio Doce sobre Drenagem Ácida de Mina, 2005.

GUSEK, J, 2005. Passive Treatment System Design, Construction and Operating Costs: How Much it Really costs Comparative to the Alternatives? In: I Workshop da Companhia Vale do Rio Doce sobre Drenagem Ácida de Mina.

LANNA, A. (1995). Gerenciamento de bacia hidrográfica: aspectos conceituais e metodológicos. IBAMA. Brasilia, 170p.

PINDYCK, R., RUBINFELD, D. (2002). Microeconomia. São Paulo: Prentice Hall, 711p.

PIRES, J., SANTOS, J. (1995). Bacias Hidrográficas. Integração entre Meio Ambiente e Desenvolvimento. In: $\mathrm{Ci}$ ência Hoje, Áquas no Brasil: má utilização e falta de planejamento. № 110. SBPC. Rio de Janeiro.

REES, B. (2005). An Overview of Passive Mine Water Treatment in Europe. In: Contemporary Reviews of Mine Water Studies in Europe, Part 2. Mine Water and the Environment, Springer-Verlag.

SANTA CATARINA (1997a). Plano de Gestão e Gerenciamento da Bacia do Rio Araranguá. Vol Il: Caracterização Hidrológica. Florianópolis: Epagri.

SANTA CATARINA (1997b). Plano de Gestão e Gerenciamento da Bacia do Rio Araranguá. Vol IV: Disponibilidade das Águas Superficiais. Florianópolis: Epagri.

SEYLER, J., FIGUEROA, L., AHMANN, D., WILDERMAN, T., ROBUSTELLI, M. (2005). Effects of Solid Phase Organic Substrate Characteristics on Sulfate Reducer Activity and Metal Removal in Passive Mine Drainage Treatment Systems. National Meeting of American Society for Mining and Reclamation.
WILDERMAN, T. GUSEK, J., VASCONCELOS, F. Passive Treatment of Mining Influenced Waters. Apresentado no I Workshop da Companhia Vale do Rio Doce sobre Drenagem Ácida de Mina, 2005.

WORLD COAL INSTITUTE (2006). The Coal Resource: a Comprehensive Overview of Coal. Disponivel em www.worldcoal.org. Acesso em 03 de abril de 2006.

\section{Water Resources Usage Planning in River Basins Subjected to Coal Mining: the Case of the Santa Catarina Carboniferous Regi on}

\section{ABSTRACT}

The environmental impacts provoked by some economic activities may cause financial damages to third parties since the cost of remediation or the one to prevent deleterious action harms and, in some cases, causes other economic activities to be impracticable. Coal mining fits into this context. In such activity, the contact of superficial water, groundwater, or rainwater with specific elements resulting from the drilling, in the presence of oxygen and microorganisms, forms the acid mine drainage (AMD) that, to a large extent of the cases, runoff in adjacent rivers, jeopardizing other uses of that water. Thus, the present work aims to elaborate a methodology of the mineral coal exploitation planning in river basins that achieves the excellent production of the ore with the costs of effluent treatment and closu re in ternalized (en vironmental costs) so that water quality parameters are respected and there is no incidence of damages to third parties. Such methodology is based on the elaboration of an optimization model that is capable to represent, during the mine's exploitation time, the load of pollutants launched in the river basin's water. Keywords: Acid M ining Drainage, River Basin, Optimization. 